\title{
Information Technology Integration Effect on Operational Performance of Kenya's Public Health Sector
}

\author{
Anne W. Mbugua ${ }^{a^{*}, \text { Juliana M. Namada }}{ }^{b}$ \\ ${ }^{a, b}$ United States International University, Africa \\ annkamb@yahoo.com
}

\begin{abstract}
The purpose of the research is to examine the effect of information technology integration on the operational performance of the of Kenya's public health sector level five hospitals in Kenya. The study examined the moderating role of public procurement to the relationship between information technology integration and operational performance. To test the extent of information technology integration and relationship with the operational performance of level five hospitals in Kenya was empirically tested utilizing a causal, non-experimental, and crosssectional research design. Regression analysis was carried out based on data from 164 respondents. In general, the study results support the idea that information technology integration has a significant effect on operational performance $(\beta 1=0.411, p<0.05)$ with $R^{2}$ of 0.449 implying that $44.9 \%$ of the variation of operational performance is attributed to information technology integration. Information technology integration is vital in coordinating the SCI dimensions leading to the improved operational performance of the health facilities. It finds that public procurement mediates the relationship between information technology integration and operational performance of the health sector as it is an enabler of improved working relationships with the suppliers.
\end{abstract}

\section{Article Info}

- Received : July 1, 2019

- Revised : August 16, 2019

- Published : September 15, 2019

- No. Pages : 226-239

- DOI : 10.33019/ijbe.v3i3.236

- JEL : H11, N7

- Keywords : supply chain integration, information technology integration, operational performance, public procurement, kenya

\section{Introduction}

Globally, Supply chain integration (SCI) though a modern concept has resulted in performance improvement in countries such as Australia, United Kingdom, France, Canada, United States of America and more recently Malaysia among others (Anjum, Kashif \& Riaz, 2016). SCI is an integrative philosophy utilized by the firms to achieve their strategic goals, through the acquisition of external resources and the elimination of the traditional functional process within the company (Childerhouse \& Towill, 2011; Schoenherr \& Swink, 2012; Yuen \& Thai, 2016). Worldwide, most firms have embraced SCI by only performing what they do best based on the organizations' core competencies and partnering with other firms to provide other resources not available internally to create value for the customers (Flynn, Huo, \& Zhao, 2010: Zhao, Huo, Selen, \& Yeung, 2011). 
One of the documented benefits accruing to the organization in SCI context is a performance improvement, efficient operations, satisfied customers (Sammuel \& Kashif, 2013). Numerous studies have documented the benefits accruing from a backward organization integration (supplier integration) and forward (customer integration). The recent advancement in information technology (IT) has enabled organizations to collaborate with various partners in the supply chain resulting in significant cost savings, visibility, dynamism and flexibility (Paulraj, Chen, \& Chung, 2006). Furthermore, IT has led to a significant transformation in the business process leading efficient and transparent processes (Bourgeois, 2014). Despite the benefits of SCI, scholars have to recommend further studies geared towards understanding better the intricacies of attaining superior SCI linkages (Basnet \& Wisner, 2012). Despite the above benefits, the health sector is unique compared to other sectors because it is characterized by sophisticated technologies as well as a varied group of stakeholders and a dynamic environment making it difficult to transfer some of the best practices in SCI available to the manufacturing or retail sectors to the healthcare sector (De Vries, \& Huijsman, 2011).

A plethora of SCI definitions has dominated most studies as well as the identification of SCI dimensions (Ding, 2016). The identification and advancement of SCI theory are of importance to both practitioners and academicians (Fabbe-Costes \& Jahre 2008) and will lead to concrete theory-building. The SCI study findings have not been consistent especially on the relationship between SCI dimensions and operational performance (Sousa, Oliveira, van der Vaart, Pieter van Donk, Gimenez, \& Sierra 2012; Gimenez, van der Vaart, \& van Donk, 2012), some reported positive impact (Kim 2009), while others posited non-significant effect (Flynn et al., 2010) and significant negative relationship (Swink et al., 2007). The differing results are attributed to issues relating to different operationalization and conceptualization of SCI, different industry and country context and the utilization of different performance measurement (Ebrahimi 2015; Zhao, Huo, Sun, \& Zhao, 2013). Furthermore, SCI is a multidimensional construct, and several studies have identified varying dimensions, some have classified SCI into two-external and internal integration; others have identified internal, supplier and internal integration (Koufteros et al. 2010; Flynn et al. 2010; Zhao et al. 2011). Others have identified SCI to include information, relational and operational integration (Leuschner, Rogers, \& Charvet, 2013), while Danese and Bortolotti (2014) have identified four SCI dimensions which are supplier, customer, internal integration and supply chain planning integration. Additionally, the SCI concept has in most instances been examined in the manufacturing context but recently been studied/implemented in the service sector as well as healthcare to replicate the superior performance (Lega, Marsilio, \& Villa, 2013; Pinna, Carrus, \& Marras, 2015).

The importance of information technology integration as a strategic constituent of SCI is highlighted by Sabir, \& Irfan, (2014), as offering an enabling solution for smooth operations in the organization. Information technology integration facilitates the members to exchange information as well as enables real-time information sharing, thus increasing visibility (Prajogo \& Olhager, 2012). Kim (2013) has introduced the concept of Integrative Information Technology in the context of SCI and has defined it as being the technology that enables the collection of relevant information relating to critical business processes while ensuring that the same is shared across all functional areas as well as across the firm boundaries. From the above definition, IT integration is essential in ensuring internal and external integration. Information systems are essential to managing the supply chain integration, also referred to as the glue that holds the chain together. Organizations are appreciating the increasing need to automate all the SCI processes to enable visibility (Mashiloane, Mafini \& Pooe, 2018). Operational performance measurement of the public health sector is vital to the policy-makers by offering the opportunity to fortify improvement and accountability of the health system (Gori, Baldini, 
\& Ciani, 2011; Mustaffa \& Potter, 2009). According to Tarifa-Fernandez and De BurgosJiménez (2017), several exogenous factors affect the relationship between SCI and operational performance and have identified 74 moderating variables. This study has incorporated public procurement as a moderating variable to the relationship between SCI, and operational performance are numerous. Although many studies, both globally and locally, have focused on assessing how SCI strategies influence operational performance, none of these studies has assessed the impact of SCI on the Kenyan public health sector.

Information Technology integration is vital in enabling the linkage of downstream (customer integration) and upstream (supplier integration) which in the government involves public procurement. This study endeavoured to bridge the gap between the researches carried out in the developed countries and more so in the manufacturing sector and replicating them in the health sector. The health sector is critical in meeting Kenya big four Agenda and universal health coverage. The primary objective of the study is to determine the effect of the IT integration and the operational performance of the of Kenya's public health sector level five hospitals in Kenya. Additionally, the study examined the moderating role of public procurement of the relationship. Literature informs the conceptual framework proposed for this study within the SCI and operational performance.

\section{Literature Reviews}

Supply Chain Integration (SCI) is the degree to which an organization strategically collaborates with its partners in managing intra and inter-organizational processes, to achieve effective and efficient flows of products and services, information, money, and decisions to provide value to customers (Flynn et al., 2010). In the global context, SCI has been viewed as being both an effective and an efficient mechanism by which firms seek to secure competitive advantage by ensuring that the operational costs are reduced and at the same time guaranteeing high customer service. In the recent past, scholars have made contributions to supply chain integration and firm performance by alienating the several dimensions such as supplier, internal, information technology and customer integration and the effect on the organizational performance (Flynn et al., 2010; Stevens \& Johnson, 2016).

The introduction of new technological innovation has allowed access to real-time, up-to-date information across the entire supply chain, which is having a significant impact on how organization are doing and expect to do business. Integration of information technology is informed by the need to allow quicker and easier connectivity between suppliers and their customers. It enhances the visibility of the customers whose needs and expectations are changing with regards to response times, delivery times, and transparency (Iyer, Germain \& Claycomb, 2009). Several studies have found that organization that has implemented IT integration have enhanced information sharing in may benefit from in various ways, which include a reduction in inventory levels, operational costs, automation of routine functions, better data documentation, and communication, etc. (Paulraj, Lado \& Chen, 2008; Madlberger \& Roztocki, 2010; Leuschner et al., 2013; Chavez et al., 2015).

Information Technology recognized as the centrepiece of the organizational structure that acts as an enabler of SCI (Hudnurkar, Jakhar, and Rathod, 2014) without IT, SCI can't achieve positive performance (Ngai, Chau, \& Chan, 2011). IT integration has two components mainly the capabilities and information sharing, which, according to Prajogo and Olhager (2012) has significant effects on integration. Researchers have concluded that information sharing with the internal and external parties such as the supplier and functional departments is a good 
precondition for external integration which leads to optimization (Hughes \& Perrons, 2011; Zhao et al., 2011). For example, in customer integration, according to Flynn et al. (2010), is the forward integration which links company technology and infrastructures such as point of sales (POS) system, inventory management system, and customer ordering system.

Information technology integration assists the organization to communicate with customers resulting in increased accuracy in terms of the demand planning and the speed of meeting demand variations (Droge, Vickery, \& Jacobs, 2012; Flynn et al., 2010; Huo, 2012; Vickery et al., 2003). Information technology integration also ensures the resource requirement which is subsequently communicated to the supplier's assisting in forecasting given that the company can predict customer demands to lead to the operational performance given that the demand uncertainty ordinarily faced by the suppliers is eradicated (Danese \& Romano, 2012). Information technology integration is an enabler as of organization performance as postulated by Lee, Kwon, and Severance (2007) and extends to coordination and resource sharing and the organizational relationship linkages. Most of the technologies used in information sharing are the Electronic Data Interchange (EDI) and other systems like the Enterprise Resource Planning (ERP) systems used for back-office operations, Customer Relationship Management for frontend information, and Collaborative Planning. Some of the industries that are best in the class when it comes to information technology are in the retail chain. An example of this is the WalMart retail chain which combines the collaborative Planning, Forecasting and Replenishment and Enterprise Resource Planning in sharing information that leads to supply chain integration in the whole spectrum (Moons, Waeyenbergh, \& Pintelon, 2018; Zhao et al., 2013).

In Kenya, IT integration is linked through an e-platform adoption referred to as the integrated financial management information system (IFMIS), which is driven by the Public Financial Management system (Asumba, 2010). The main aim is to instil fiscal discipline, strategic and efficient allocation of government funds and ensure value for money in the use of public funds. The IFMIS is supposed to address different aspects of IT integration, such as data and information sharing. The IFMIS functionalities are vital in ensuring SCI coordination, which increases the operational performance of the organization. Kiilu and Ngugi (2014) have posited that the implementation of IFMIS has resulted in the enhancement of effective management of public funds, automation of government processes, reporting, record keeping, and enhanced communication, customization and integration of government processes.

In any country, the size of public procurement is usually quite considerable and often accounts for a significant proportion of goods and services demanded. Lewis, Balaji and Rai, (2010) argue that public procurement is an economic instrument for developing any society or nation. Procurement activities are very critical for all organizations from small households, firms and government institutions such as public schools, hospitals, and state corporations. From a practical point of view, procurement is an essential activity and its successful accomplishment informs the performance of the organization. Procurement in the private sector is a venture in profit maximization and cost savings. In the public sector, public concern and efficiency drive the procurement process (Mathew, John \& Kumar, 2013).

Procurement excellence, according to Schiele and McCue, (2006), is an increasingly important factor in delivering efficient operations within government institutions. The institutions must consider every avenue that will result in cost reduction, and the procurement department plays a vital role in achieving this strategic goal. One way of achieving this is by incorporating the best value for money principals in public procurement rather than the lowest initial price (Kiragu, 2012). Effective and efficient public procurement systems and collaborative 
relationships with suppliers are critical to the accomplishment of organizational goals, performance and cost reduction. Public procurement policies developed a focus on attaining operational efficiency by emphasizing the need for public institutions to minimize redundancy and by leveraging the on resources that contribute most to its success and employing the best of its technology, workforce and business processes. The realized reduced internal costs attributable to operational efficiency enable these institutions to attain better performance outcomes (Davis, Stremikis, Schoen, \& Squires, 2014).

The independent variable for the study is operational performance. To measure firm performance, various models have been utilized, including financial, business, and operational performance. For this study, given that public health facilities primary motivation is not profit but instead value to the citizens, operational performance is recommended. Operational performance mainly utilizes constructs that measure among other management costs, lead-time and order-time (Heizer, Render \& Weiss, 2017). Operational performance is a critical contributor to the overall performance of the supply chain as it is an amalgamation of multiple factors (Lu, Ding, Asian, \& Paul, 2018). The three operational performance models that dominate literature are the balanced scorecard proposed by Kaplan and Norton, (1992; 1996; 1997), the decision-making levels by Gunasekaran, Patel, and McCaughey (2004) besides the supply chain operations reference, (SCOR) model. Most of these frameworks are derived from a manufacturing context, and there are relatively few attempts that systematically recommend a model to measure the performance of the service supply chain integration and by extension the public sector (Gunasekaran \& Kobu, 2007).

SCI does not have theories of its own, and there have been calls for more empirical studies with the aim of theory building. SCI involves resources which include monetary, material, information, and knowledge sharing to meet customer needs. This study is primarily anchored on two theories, the agency theory, and the RBV. The agency theory is associated with Alchian and Demsetz (1972); Jensen and Meckling (1976). The theory explains how best to organize relationships in which one party (principal) determines the work and which another party (agent) performs or makes decisions on behalf of the principal. In SCI, the companies become partners as opposed to the traditional view of business contracts. Furthermore, in the public sector, the procurement staff act as agents in the context of delegated authority to spend public funds. The IT Integration and public procurement are anchored on this theory, especially because of proprietary rights of the IT and the usage of public funds.

The other theory is the RBV introduced by Penrose (1959) and posits that a firm comprises of a bundle of unique resources. The RBV explains the relationships between firm capabilities, resources, and competitive advantage. SCI involves collaboration with suppliers to gain access to knowledge/skills found in the other firms which include monetary, material, information, and knowledge sharing to meet customer needs (Stevens \& Johnson, 2016). Information Technology as a resource capable of having competitive advantage is anchored in RBV theory, and the information technology integration resource is easily imitable by other organizations, and for it to qualify under the VRIN framework, the technology must be difficult to imitate by competitors (Glenn Richey Jr, Chen, Upreti, Fawcett, \& Adams, 2009; Wu, Yeniyurt, Kim, \& Cavusgil, 2006). The study uses the configurational approach which, according to Cao, Huo, $\mathrm{Li}$, and Zhao, (2015), explains how the IT integration (independent variable), public procurement (moderating variable) interact with the operational performance (dependent variable). The first hypothesis relating to information technology integration and the influence on the operational performance Kenya's public health sector utilized among other parameters proposed by Lee et al., (2007); Mukaddes, Rashed, and Abdul, (2010); Prajogo and Olhager, 
(2012); Paulraj et al., (2008) indicators in relation to sharing sensitive information between the partners with regular face-to-face planning and exchange of performance feedback.

\section{H01: Information technology integration has no significant influence on the operational performance of Kenya's public health sector.}

On the public procurement the study incorporated the indicators proposed by Msimangira (2010) and the public procurement requirements as stipulated in the Public Procurement and Disposal Act, (2015) such as the requirement to prepare annual procurement plans, the publication of procurement plans, procurement complains mechanism, debriefings, prequalification of contractors.

\section{Ho2: Public Procurement has no significant moderating influence on the relationship between SCI and the operational performance of Kenya's public health sector.}

The conceptual model (Figure 1) provides further insights into the complex relationships that exist in the public sector SCI.

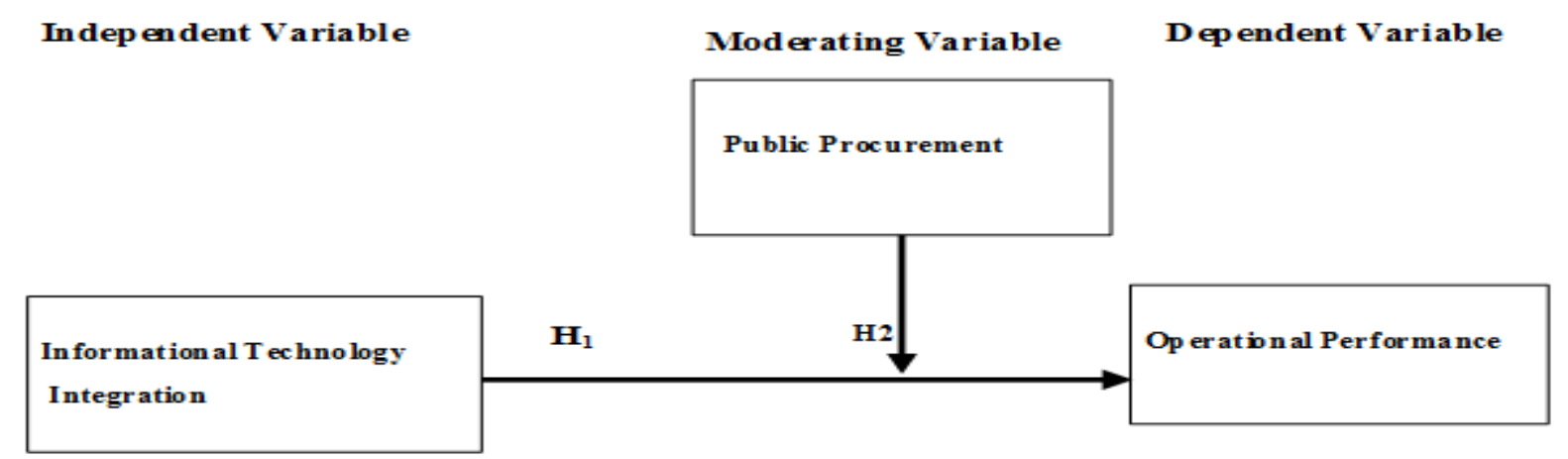

Figure 1. Conceptual Model

\section{Research Methods}

Post-positivist philosophy was adopted given it is ideal in enabling empirical examination of the influence between information technology integration and operational performance in Kenya's public health sector. The post-positivist approach diminishes the complexity enabling the researcher to examine the causal relationships between the three study constructs. The research design adopted was causal, non-experimental and cross-sectional and took a confirmatory element based on prior hypotheses deduced from existing empirical studies. Mixed-Method research was utilized involving both quantitative and qualitative techniques. The study collected information from all Level five public facilities which, according to Kenya, new dispensation receives funding from the national government. The respondents were selected through simple random sample based on Slovin's Formula (Ryan, 2013). One hundred and eighty-six respondents drawn from personnel involved in the supply chain activities of the public health sector. Which included biomedical engineers, county staff, chief nurses, hospital secretary, procurement officers, information technology officers, finance officers, public health officers, medical superintendents, pharmacists, chief laboratory technician.

The study utilized a closed-ended semi-structured questionnaire with Likert scales from 5-1 and ranging from strongly disagree to strongly agree. The questionnaire was favoured because it enabled the respondents to answer the questions quickly. Furthermore, it allowed the study to use the quantitative approach effectively with the use of statistics for data interpretation. The 
questionnaire also included general information such as demographic data of the respondents. To measure the validity and reliability of the data collection instruments, a pilot study was conducted. The Cronbach's alpha test to estimate the proportion of variance that is consistent in the test scores. Ten items were considered for all the independent variables, while 24 items were considered for measuring operational performance. The Cronbach's alpha test score for estimation of the proportion of variance test results are presented in Table 1.

Table 1: Reliability Analysis

\begin{tabular}{lcccc}
\hline Variable & No of Items & Respondents & $\alpha=$ Alpha & Comment \\
\hline IT Integration & 10 & 11 & .923 & Reliable \\
Procurement & 10 & 11 & .937 & Reliable \\
Operational Performance & 24 & 11 & .970 & Reliable \\
\hline
\end{tabular}

Cronbach's Alpha coefficient was higher than 0.7 for all the variables. Therefore, no editing was required for the instrument as far as the independent and the dependent variables were concerned.

\section{Results}

The study applied both inferential and descriptive statistics. The descriptive statistics summarized information on demographics such as gender, education level, age, and employment. Inferential statistics were utilized to test the study hypotheses. The study distributed 196 questionnaires to the level five health facilities employees and county officials. One hundred sixty-four questionnaires returned, which represented $83.7 \%$ response rate. To ensure that all the assumptions of regressions are fulfilled, the study, undertook diagnostics tests among them linearity normality, autocorrelation and multi-collinearity. The collected data satisfied the assumptions for multiple linear regression. The casual relationship among the study variables was tested using regression analysis. The estimates of the regression coefficients explaining the relationship between the operational performance (dependent), IT integration (independent variables) are illustrated in Table 2.

\section{Table 2: Model Summary}

\section{Model Summary}

\begin{tabular}{lcccc}
\hline Model & $\mathrm{R}$ & R Square & Adjusted R Square & $\begin{array}{c}\text { Std. Error of the } \\
\text { Estimate }\end{array}$ \\
\hline 1 & $.654^{\mathrm{a}}$ & .428 & .424 & .39055 \\
\hline a. & Predictors: (Constant), IT Integration \\
b. & Dependent Variable: Operational performance of Kenya's public health sector
\end{tabular}

The outputs indicated that the strength of association between the dependent variable and the independent variables was moderately high $(\mathrm{R}=0.654)$. The $\mathrm{R}$-square was found to be 0.428 . This is the explanatory power of the model which shows that $42.8 \%$ of the variation in the dependent variable (operational performance) is explained by the variation of predictors in the model. Which implies that there is the existence of other factors not studied in this research explains the remaining $57.2 \%$ of the operational performance of Kenya's public health sector. The analysis of variance is presented in Table 3, illustrating that the overall model linking information technology integration and operational performance when moderated by public procurement was statistically significant. 
Table 3: ANOVA Table

\begin{tabular}{llrrrrr}
\hline & & \multicolumn{3}{c}{ Anova $^{\mathrm{a}}$} & & \\
Model & & Sum of Squares & Df & Mean Square & F & Sig. \\
\hline 1 & Regression & 19.375 & 2 & 9.687 & 65.566 & $.000^{\mathrm{b}}$ \\
& Residual & 23.788 & 161 & .148 & & \\
& Total & 43.162 & 163 & & & \\
\hline
\end{tabular}

a. Dependent Variable: Operational Performance of Kenya's public health sector

b. Predictors: (Constant), IT Integration, Public Procurement

The values presented in Table 3 The results imply that the regression model for the study has a less than 0.05 probability of giving a wrong prediction. The regression model has a confidence level of above $95 \%$ hence high reliability of the results. Regression analysis is a statistical test utilized to examine the relationship between the independent and the dependent variables. The study dependent variable is the operational performance of the Kenya health sector public sector, while the independent variables were information technology integration. The study was based at $95 \%$ confidence level to identify the model predictor variables. The estimates of the regression coefficients, the t-statistics and the p-values for the relationship between the operational performance, which is the independent variable and the dependent variables are illustrated in Table 4.

Table 4: Regression Coefficients

\begin{tabular}{|c|c|c|c|c|c|c|}
\hline \multicolumn{7}{|c|}{ Coefficients } \\
\hline \multirow{2}{*}{\multicolumn{2}{|c|}{ Model }} & \multicolumn{2}{|c|}{$\begin{array}{l}\text { Unstandardized } \\
\text { Coefficients }\end{array}$} & $\begin{array}{l}\text { Standardized } \\
\text { Coefficients }\end{array}$ & \multirow[b]{2}{*}{$\mathrm{T}$} & \multirow[b]{2}{*}{ Sig. } \\
\hline & & B & Std. Error & Beta & & \\
\hline \multirow[t]{2}{*}{1} & (Constant) & 1.846 & .187 & & 9.850 & .000 \\
\hline & IT Integration & .533 & .048 & .654 & 10.999 & .000 \\
\hline
\end{tabular}

a. Dependent Variable: Operational Performance of Kenya's public health sector

The findings show that information technology integration significantly influenced operational performance. The three variables had a significant value less than the level of significance $(\alpha=0.05)$.

The Constant term is $=1.846 ; \beta_{1}=0.533 ; \mathrm{X}_{1}=$ Information Technology integration

From the results, when all the variables are held constant, a unit change in Information Technology Integration leads to a $53.3 \%$ increase in operational performance. Public procurement was the moderating variable in the study when introduced, and a regression model run, the results are illustrated in Table 5.

Table 5: Model Summary Public Procurement and IT Integration

\begin{tabular}{|c|c|c|c|c|}
\hline \multicolumn{5}{|c|}{ Model Summary } \\
\hline Model & $\mathrm{R}$ & R Square & Adjusted R Square & Estimate \\
\hline 1 & $.670^{\mathrm{a}}$ & .449 & .442 & .38438 \\
\hline
\end{tabular}

a. Predictors: (Constant), IT Integration, Public Procurement

b. Dependent Variable: Operational performance of Kenya's public health sector 
The regression analysis model presented in Table 6 shows that there was a relatively strong linear relationship between IT integration and operational performance when moderated by public procurement, as shown by an $\mathrm{R}^{2}=0.44$. The results imply that $44.9 \%$ of the variation in the operational performance of Kenya's public health sector attributed to changes in IT integration and public procurement. Accordingly, 55.1\% of the variation in the operational performance of Kenya's public health sector can, therefore, be explained by other variables other than IT integration and public procurement.

Table 6: Regression Coefficient's for Public Procurement and IT Integration

\begin{tabular}{|c|c|c|c|c|c|c|}
\hline \multicolumn{7}{|c|}{ Coefficients } \\
\hline \multirow{2}{*}{\multicolumn{2}{|c|}{ Model }} & \multicolumn{2}{|c|}{$\begin{array}{l}\text { Unstandardized } \\
\text { Coefficients }\end{array}$} & \multirow{2}{*}{$\begin{array}{c}\text { Standardized } \\
\text { Coefficients } \\
\text { Beta } \\
\end{array}$} & \multirow[b]{2}{*}{$\mathrm{T}$} & \multirow[b]{2}{*}{ Sig. } \\
\hline & & $\mathrm{B}$ & Std. Error & & & \\
\hline \multirow[t]{3}{*}{1} & (Constant) & 1.492 & .233 & & 6.414 & .000 \\
\hline & Public Procurement & .213 & .085 & .209 & 2.498 & .014 \\
\hline & IT Integration & .411 & .068 & .505 & 6.050 & .000 \\
\hline
\end{tabular}

a. Dependent Variable: Operational Performance of Kenya's public health sector

From Table 6, IT Integration as a dimension of supply chain integration has a positive and significant effect on operational performance. The results imply that a unit increase in IT integration leads to a change of 0.411 in operational performance. Further, the moderating variable has a significant effect on operational performance, and a unit increase in public procurement would lead to a change of 0.213 in operational performance. The study showed that the variations of operational performance explained by IT Integration increased from $42.8 \%$ to $44.9 \%$ when the moderating variable was introduced in the model. The regression analysis, therefore, shows that public procurement significantly moderated the relationship between IT integration and operational performance. Thus, we can conclude that public procurement moderated the relationship between IT integration and operational performance of the Kenya public health sector. The optimal linear regression model showing how public procurement affects the relationship between IT integration and operational performance Kenya's public health sector was:

The Constant term is $=1.492 ; \beta_{1}=0.411 ; \beta_{2}=0.213$

Using the regression model in Table 5, two hypotheses for the study were tested. The study findings $(b=0.411, p<0.05)$ established that IT integration had a significant impact on the operational performance of Kenya's public health sector; hence, the null hypothesis was rejected. The second hypothesis of the study asserted that public procurement had no significant moderating influence between IT integration and operational performance. The study findings $(b=0.213, p<0.05)$ established that public procurement had a significant moderating influence between IT integration and the operational performance of Kenya's public health sector.

\section{Discussion}

The purpose of this study was to examine the relationship between information technology integration and the operational performance of Kenya's public health sector's Level five hospitals in Kenya. Additionally, the study examined the moderating role of public procurement on the relationship. In general, the study results support the idea that information technology integration has a significant effect on operational performance. Information 
technology integration is vital in coordinating the SCI dimensions leading to the improved operational performance of the health facilities It finds that public procurement mediates the relationship between information technology integration and operational performance of the health sector as it is an enabler of improved working relationships with the suppliers.

Information technology (IT) integration is crucial as it is the glue that joins the processes hence increasing the efficiency and productivity of the health facilities. When all data is kept together, organized, accessible, and easily shared between platforms or software, it saves health facilities time and resources. The study, therefore, concludes that effective IT integration is a definitive solution to counter barriers such as undesirable inventory turnover and inconsistent lead time of goods and services. The study concluded that the installation of planning software and automation of management inventory had given health facilities the capability of real-time processing of information both internally and externally. The results are in tandem with an earlier study by Hudnurkar, Jakhar and Rathod (2014), Prajogo and Olhager, (2012); Ajmera and Cook (2009), that IT integration is the centrepiece and acts as an enabler of SCI and superior performance.

The study also concludes that health facilities have aligned their acquisition/procurement plan to the established standards of procurement and published or shared with their suppliers to avoid mismanagement of resources and increase transparency. The study identified the existence of a robust Public Procurement system promotes fair and equitable supplier integration by providing visibility and transparent process of the public procurement cycle. This is in concurrence with Bartolini (2012), who concluded that public procurement in the improvement of healthcare performance.

\section{Conclusion, Recommendation and Further Studies}

\section{Conclusion}

Health facilities to integrate their entire supply chain network to be able to exchange data with their suppliers using technology and capabilities already present. The study also concluded that effective IT integration is a definitive solution to counter barriers such as undesirable inventory turnover and inconsistent lead time of goods and services and should leverage this capability in procurement, customer needs and visibility of inventory. Information technology (IT) integration is essential as it is the glue that joins the processes hence increasing the efficiency and productivity of the health facilities. When all data is kept together, organized, accessible, and easily shared between platforms or software, it saves health facilities time and resources. The study, therefore, concludes that effective IT integration is a definitive solution to counter barriers such as undesirable inventory turnover and inconsistent lead time of goods and services. The study concluded that the installation of planning software and automation of management inventory had given health facilities the capability of real-time processing of information both internally and externally. The results are in tandem with an earlier study by Hudnurkar, Jakhar and Rathod (2014), Prajogo and Olhager, (2012); Ajmera and Cook (2009), that IT integration is the centrepiece and acts as an enabler of SCI and superior performance.

Public procurement was noted to be important in the relationship between SCI dimensions and operational performance as it leads to the efficient and effective management of the resources of health facilities. Furthermore, it ensures that integrity is upheld in the entire supply chain as well as the reduction of wastage and mitigation of risk (Kanyoma, Khomba, Sankhulani, \& Hanif, 2013). Besides, the study determined that it was prudent for health facilities to integrate their entire supply network backwards and forward to enable the exchange of variable data 
with their suppliers using the technology and capabilities they already present. Therefore, interacting with suppliers in a manner they are already capable of is desirable because it will not be perceived as a source of additional costs and disruptions.

\section{Recommendation}

The study recommends robust and effective IT Integration by strengthening their capabilities in the system, data, and process. The study also advocates for the facilities to consider involvement and communication of their processes to suppliers to increase their confidence in the process and bring them on board to understand the facility's requirements and make them committed to delivering the facilities' expectations. Consider incorporating as part of their customer integration process, the collection, and dissemination of essential data of patients who visit their establishments. The study recommends that facilities need to develop secure and electronic health records of patients, which will make health information available electronically and readily accessible for decision making.

\section{Further Studies}

The study recommends that future studies consider investigating the impact of other factors that were not found to be significant in this study. Such information will inform the health facilities on how to sufficiently integrate these aspects of SCI. Given that SCI is dynamic, it would be interesting to have a study conducted over time to examine the effect of supply chain integration dimensions and operational performance and examine the multiplicative impact over time. Furthermore, future studies, given the dynamism SCI, should incorporate exogenous variables that mediate on the effect of SCI dimensions on operational performance.

\section{References}

1) Ajmera, A., \& Cook, J., (2009). A multi-phase framework for supply chain integration. SAM Advanced Management Journal, 74(1), 37.

2) Anjum, A., Kashif, M. T., \& Riaz, W. (2016). Supply Chain Integration and Operational Performance: Moderating role of Organizational Culture. International Journal of Academic Research in Business and Social Sciences, 6(12), 2222-6990.

3) Asumba, G. (2010). B2B progress in Italian organization, A multiple case study. Human Resources Procurement Journal, 21(3), pp. 275- 292.

4) Basnet, C., \& Wisner, J. (2012). Nurturing internal supply chain integration. Operations and Supply Chain Management, 5(1), 27-41.

5) Bourgeois, D. (2014). Information systems for business and beyond. The Saylor Foundation.

6) Cao, Z., Huo, B., Li, Y., \& Zhao, X. (2015). The impact of organizational culture on supply chain integration: a contingency and configuration approach. Supply Chain Management: An International Journal, 20(1), 24-41.

7) Chavez, R., Yu, W., Gimenez, C., Fynes, B., \& Wiengarten, F. (2015). Customer integration and operational performance: The mediating role of information quality. Decision Support Systems, 80, 83-95.

8) Childerhouse, P., \& Towill, D. R. (2011). Arcs of supply chain integration. International journal of production research, 49(24), 7441-7468.

9) Danese, P., 2013, Supplier integration and company performance: A configurational view: Omega. International Journal of Management Science, v. 41, p. 1029-1041. 
10) Danese, P., \& Bortolotti, T., (2014). Supply chain integration patterns and operational performance: a plant-level survey-based analysis. International Journal of Production Research, 52(23), 7062-7083.

11) Danese, P., and P. Romano, 2013, The moderating role of supply network structure on the customer integration-efficiency relationship. International Journal of Operations \& Production Management, v. 33, p. 372-393.

12) Davis, K., Stremikis, K., Squires, D., \& Schoen, C. (2014). Mirror, mirror on the wall. How the performance of the US Health care system compares internationally. New York: Commonwealth Fund.

13) de Vries, J., Huijsman, R., Aronsson, H., Abrahamsson, M., \& Spens, K. (2011). Developing lean and agile health care supply chains. Supply chain management: An international journal.

14) Ding, Yi (2016) From supply chain integration to operational performance: the moderating effect of demand uncertainty. $\mathrm{PhD}$ thesis, University of Warwick.

15) Droge, C., Vickery, S. K., \& Jacobs, M. A. (2012). Does supply chain integration mediate the relationships between product/process strategy and service performance? An empirical study. International Journal of Production Economics, 137(2), 250-262.

16) Ebrahimi, S. M., (2015). Examining the impact of supply chain integration on organization structure and operational performance in oil and gas supply chains: A contingency approach (Doctoral dissertation, University of Sheffield).

17) Fabbe-Costes, N., \& Jahre, M., (2008). Supply chain integration and performance: a review of the evidence. The International Journal of Logistics Management, 19(2), 130154.

18) Flynn, B. B., Huo, B., \& Zhao, X. (2010). The impact of supply chain integration on performance: a contingency and configuration approach. Journal of operations management, 28(1), 58-71.

19) Glenn Richey Jr, R., Chen, H., Upreti, R., Fawcett, S. E., \& Adams, F. G. (2009). The moderating role of barriers on the relationship between drivers to supply chain integration and firm performance. International Journal of Physical Distribution \& Logistics Management, 39(10), 826-840.

20) Gimenez, C., van der Vaart, T., \& Pieter van Donk, D. (2012). Supply chain integration and performance: the moderating effect of supply complexity. International Journal of Operations \& Production Management, 32(5), 583-610.

21) Gori, C., Baldini, M., \& Ciani, C. (2011). Performance measurement for health system improvement experiences, challenges and prospects. Health Aff, 30, 590-595.

22) Gunasekaran, A., \& Kobu, B. (2007). Performance measures and metrics in logistics and supply chain management: a review of recent literature (1995-2004) for research and applications. International journal of production research, 45(12), 2819-2840.

23) Gunasekaran, A., Patel, C., \& McGaughey, R. E. (2004). A framework for supply chain performance measurement. International journal of production economics, 87(3), 333347.

24) Heizer, J.H., Render, B. and Weiss, H.J. (2008), Principles of Operations Management, Pearson Prentice Hall, PA.

25) Hudnurkar, M., Jakhar, S., \& Rathod, U. (2014). Factors affecting collaboration in the supply chain: A literature review. Procedia-Social and Behavioral Sciences, 133, 189-202

26) Hughes, M., \& Perrons, R. K. (2011). Shaping and re-shaping social capital in buyersupplier relationships. Journal of business research, 64(2), 164-171.

27) Iyer, K.N., Germain, R. \& Claycomb, C., (2009). B2B e-commerce supply chain integration and performance: A contingency fit perspective on the role of the environment. Information \& Management 46(6), 313-322. 
28) Jonsson, P., \& Mattsson, S. (2013). The value of sharing planning information in supply chains. International Journal of Physical Distribution \& Logistics Management, 43(4), 282-299.

29) Kanyoma, K. E., Khomba, J. K., Sankhulani, E. J., \& Hanif, R. (2013). Sourcing Strategy and Supply Chain Risk Management in the Healthcare Sector: A Case Study of Malawi's Public Healthcare Delivery Supply Chain. Journal of Management and Strategy, 4(3), 16.

30) Kiilu, M., \& Ngugi, K., (2014). Effect of Public Financial Management Reforms in the Effective Management of Public Funds in Kenya: A Case Study of the National Treasury. European Journal of Business Management, 2(1), 161 - 169.

31) Kiragu, R. W. (2012). Information Technology and the procurement process in Kenya (Doctoral dissertation).

32) Koufteros, X., Rawski, G. E., \& Rupak, R. (2010). Organizational integration for product development: the effects on glitches, on-time execution of engineering change orders, and market success. Decision Sciences, 41(1), 49-80.

33) Lee, C.W, Kwon, I. W. G., \& Severance, D. (2007). Relationship between supply chain performance and degree of linkage among supplier, internal integration, and customer. Supply chain management: an international journal, 12(6), 444-452.

34) Lega, F., Marsilio, M., \& Villa, S. (2013). An evaluation framework for measuring supply chain performance in the public healthcare sector: evidence from the Italian NHS. Production Planning \& Control, 24(10-11), 931-947.

35) Leuschner, R., Rogers, D. S., \& Charvet, F. F. (2013). A meta-analysis of supply chain integration and firm performance. Journal of Supply Chain Management, 49(2), 34-57

36) Madlberger, M. \& Roztocki, N., 2010, Digital cross-organizational collaboration: A metatriangulation review, European Journal of Information Systems 23, 418-428

37) Mashiloane, M. W., Mafini, C., \& Pooe, R. D. (2018). Supply chain dynamism, information sharing, inter-organizational relationships, and supply chain performance in the manufacturing sector. Acta Commercii, 18(1), 1-15.

38) Mathew, J., John, J., \& Kumar, S. (2013). New trends in healthcare supply chain. In International Annual Conference, Production and Operations Management Society, Denver, Colorado.

39) Moons, K., Waeyenbergh, G., \& Pintelon, L. (2019). Measuring the logistics performance of internal hospital supply chains-a literature study. Omega, 82, 205-217.

40) Moshkdanian, F., \& Molahosseini, A. (2013). Impact of supply chain integration on the performance of Bahman Group. Interdisciplinary Journal of Contemporary Research in Business, 5(1), 184-192.

41) Msimangira, K.A.B. (2010). Supply chain integration in New Zealand public hospitals: impact on supplier commercial relationships and order fulfilment. PhD thesis, Auckland University of Technology, New Zealand.

42) Mustaffa N., and Potter A., (2009). Healthcare supply chain management in Malaysia: a case study; Supply Chain Management: An International Journal, 14 (3).234-243.

43) Mukaddes, A. M. M., Rashed, C. A. A., Malek, A. B. M. A., Kaiser, M. J., \& Alam, S. M. S. (2010). Developing an information model for supply chain information flow and its management. International Journal of Innovation. Management and Technology, 12, 226231.

44) Ngai, E. W., Chau, D. C., \& Chan, T. L. A. (2011). Information technology, operational, and management competencies for supply chain agility: Findings from case studies. The Journal of Strategic Information Systems, 20(3), 232-249.

45) Paulraj, A., Chen, I. J., \& Chung, C. H. (2006). The role of information technology in supply chain integration. International journal of information systems and change management, 1(2), 202-219. 
46) Pinna, R., Carrus, P. P., \& Marras, F. (2015). Emerging Trends in Healthcare Supply Chain Management-An Italian Experience. Applications of Contemporary Management Approaches in Supply Chains, INTECH.

47) Prajogo, D., \& Olhager, J. (2012). Supply chain integration and performance: The effects of long-term relationships, information technology, and sharing, and logistics integration. International Journal of Production Economics, 135(1), 514-522.

48) Ryan, G. S. (2013). Online social networks for patient involvement and recruitment in clinical research. Nurse researcher, 21(1), 35-39.

49) Sabir, R., \& Irfan, M. (2014). Levels \& Barriers to Supply Chain Integration: A conceptual model of Supply Chain Performance. International Journal of Management Science and Business Administration, 1(1), 52-59.

50) Sammuel, S., \& Kashif, H. (2013). Levels and Barriers to Supply Chain Integration: A survey on Haleeb foods distributor's in Pakistan.

51) Schiele, J. J., \& McCue, C. P. (2006). Professional service acquisition in public sector procurement: a conceptual model of meaningful involvement. International Journal of Operations \& Production Management, 26(3), 300-325.

52) Schoenherr, T., \& Swink, M. (2012). Revisiting the arcs of integration: Cross-validations and extensions. Journal of Operations Management, 30, 99-115.

53) Sousa, R., Oliveira, P., van der Vaart, T., Pieter van Donk, D., Gimenez, C., \& Sierra, V. (2012). Modelling the integration-performance relationship: Collaborative practices, enablers and contextual factors. International Journal of Operations \& Production Management, 32(9), 1043-107.

54) Stevens, G. C., \& Johnson, M. (2016). Integrating the Supply Chain... 25 years on. International Journal of Physical Distribution \& Logistics Management, 46(1), 19-42.

55) Tarifa-Fernandez, J., \& De Burgos-Jiménez, J. (2017). Supply chain integration and performance relationship: a moderating effects review. The International Journal of Logistics Management, 28(4), 1243-1271.

56) Yuen, K. F., \& Thai, V. V. (2016). The relationship between supply chain integration and operational performances: A study of priorities and synergies. Transportation Journal, 55(1), 31-50.

57) Zhao, X., Huo, B., Selen, W. and Yeung, J. (2011), "The impact of internal integration and relationship commitment on external integration". Journal of Operations Management, Vol. 29 No. 1/2, pp. 17-32. 